Gut, 1984, 25, 849-853

\title{
Partial defect of neutrophil oxidative metabolism in Crohn's disease
}

\author{
H W VERSPAGET, M A C MIEREMET-OOMS, I T WETERMAN, AND A S PEÑA \\ From the Department of Gastroenterology, University Hospital, Leiden, The Netherlands
}

SUmmary Polymorphonuclear leucocytes of patients with untreated Crohn's disease showed a lower level of oxidative metabolism than polymorphonuclear leucocytes of treated Crohn's disease patients and controls. Whereas the production of superoxide anion $\left(\mathrm{O}_{\dot{2}}^{\overline{1}}\right)$ in Crohn's disease patients was almost normal, polymorphonuclear leucocytes of untreated Crohn's disease patients showed a significantly deficient production of hydrogen peroxide $\left(\mathrm{H}_{2} \mathrm{O}_{2}\right)$. In the medically treated Crohn's disease patients, a significant negative correlation was found between $\mathrm{H}_{2} \mathrm{O}_{2}$ production by polymorphonuclear leucocytes and disease activity. These findings suggest an intrinsic cellular defect in the neutrophils of Crohn's disease patients which, together with the decreased locomotor function of these cells in vivo, might contribute to the pathogenesis of the chronic inflammation and granuloma formation in this disease.

Leucocytes are believed to play an important role in the pathogenesis of Crohn's disease. ${ }^{1}$ Defective chemotaxis in vivo and an impairment of the phagocytic process are thought to be involved in the formation of the granuloma. ${ }^{2}$ Using the skin window technique, several groups have found reduced migration of polymorphonuclear leucocytes in Crohn's disease. ${ }^{3-5}$ This defect might explain the relative paucity of polymorphonuclear leucocyte infiltration into mucosa affected by Crohn's disease.

One of the most prominent histopathological features of Crohn's disease is the presence of granulomas in the gastrointestinal tract, but similar findings have been made in chronic granulomatous disease. ${ }^{6}$ The prime defect in chronic granulomatous disease concerns the oxidative metabolism - that is, a neutrophil dysfunction which is characterised by a defect in the production of microbicidal oxygen metabolites - for example, superoxide anion $\left(\mathrm{O}_{\dot{2}}^{\overline{1}}\right)$ and hydrogen peroxide $\left(\mathrm{H}_{2} \mathrm{O}_{2}\right)$; during phagocytosis. It has been postulated that this defective primary defence mechanism is responsible for the granulomatous reactions seen in chronic granulomatous disease. ${ }^{6}$

These findings raised the question whether the oxidative burst of polymorphonuclear leucocytes is also defective in Crohn's disease patients. Previous

\footnotetext{
Address for correspondence: Dr H W Verspaget, Dept of Gastroenterology, Academisch Ziekenhuis Leiden. Rijnsburgerweg 10, 2333AA, Leiden. The Netherlands.

Received for publication 2 November 1983
}

studies had shown that during phagocytosis the nitro blue tetrazolium reduction could be either normal, enhanced, or reduced, and that the luminescence was impaired, ${ }^{4-9}$ but these results were not conclusive, probably because of the 'non-discriminative' techniques used. The aim of the present study was to evaluate the oxidative capacity of polymorphonuclear leucocytes from Crohn's disease patients, with the use of more specific techniques to measure $\mathrm{O}_{2}^{\overline{2}}$ and $\mathrm{H}_{2} \mathrm{O}_{2}$ production separately.

\section{Methods}

PATIENTS

The present series comprised 43 patients with Crohn's disease. The diagnosis was based on characteristic clinical, endoscopic, histological, and radiological features. The mean age of the 43 Crohn's disease patients ( 24 women, 19 men) was 33 years (range 19-67 years). In 14 cases the disease was limited to the ileum, in eight to the colon, and 21 had ileocolonic involvement. Nineteen patients were taking salazopyrine, five were on corticosteroids, and 10 were on a combination of salazopyrine and corticosteroids. Nine patients had not taken any medication for at least six months because of clinical remission in the past, seven visited the outpatient clinic for routine control and were still in remission, and two were hospitalised owing to clinical relapse.

At the time of venepuncture, disease activity was 
evaluated in all of the Crohn's disease patients according to the Crohn's Disease Activity Index (CDAI). ${ }^{10}$

The control group comprised 29 healthy subjects (14 women, 15 men) with a mean age of 32 years (range 22-51 years).

\section{OXYGEN METABOLITES PRODUCTION}

Polymorphonuclear leucocytes were isolated from heparinised blood by Ficoll-Hypaque separation and a two-fold lysis of the erythrocytes in buffered ammonium chloride. ${ }^{11}$ The cells were washed three times with Hanks' balanced salt solution containing $0.2 \%$ bovine albumin, and counted in a haemocytometer. The polymorphonuclear leucocytes suspension was $>96 \%$ pure, the remainder being a few contaminating lymphocytes $(<4 \%)$ and monocytes $(<1 \%)$. Superoxide anion $\left(\mathrm{O}_{\dot{2}}^{\overline{ }}\right)$ production was determined as the reduction of ferricytochrome $\mathrm{C}$ (cyt C; Sigma). ${ }^{12}$ In brief, $1 \times 10^{6}$ polymorphonuclear leucocytes were incubated at $37^{\circ} \mathrm{C}$ in $1 \mathrm{ml}$ Hanks' balanced salt solution containing $100 \mu \mathrm{M}$ cyt $\mathrm{C}$ and a respiratory stimulus. We determined the $\mathrm{O}_{2}^{\overline{2}}$ production with and without stimulation. The stimuli used were: $5 \mu \mathrm{g}$ phorbol-myristate-acetate, ${ }^{13}$ $50 \mu \mathrm{g}$ concanavalin $\mathrm{A}^{14}$ (con $\mathrm{A}$ ) alone or in combination with $10 \mu \mathrm{g}$ cytochalasin $\mathrm{E}^{15}$ (cyt $\mathrm{E}$; Sigma), and $500 \mu \mathrm{g}$ lipopolysaccharide derived from Escherichia coli 0127:B8 (Difco). The incubations were not performed in duplicates because in most cases too few polymorphonuclear leucocytes were available. The incubation time was 30 minutes except for phorbol-myristate-acetate, for which it was five minutes. All reactions were stopped by rapid chilling of the reaction mixture and cooled centrifugation. Production of $\mathrm{O}_{\overline{2}}^{\bar{z}}$ or reduction of cytochrome $\mathrm{C}$ was measured spectrophotometrically and calculated with the extinction coefficient $E_{550}=2 \cdot 1 \times 10^{4} / \mathrm{M} / \mathrm{cm}$. Cell free reaction mixture served as blank. The reproducibility of this assay was $9.2 \%$ as determined by quadruplicate incubations with the same stimulus and expressed as intra-assay coefficient of variance:

$$
\frac{\text { St dev }}{\text { mean }} \times 100
$$

Hydrogen peroxide $\left(\mathrm{H}_{2} \mathrm{O}_{2}\right)$ production was determined as the oxidation of homovanillic acid, which becomes fluorescent. ${ }^{16} 17$ In brief, $1.5 \times 10^{6}$ polymorphonuclear leucocytes were incubated in 3 ml Hanks' balanced salt solution containing $0.8 \mathrm{mM}$ homovanillic acid, $60 \mu \mathrm{g}$ horseradish peroxidase, and $2 \mathrm{mM}$ sodium azide $\left(\mathrm{NaN}_{3}\right)$, to inhibit endogenous cellular peroxidase and catalase activity. Incubation conditions and stimuli were the same as for $\mathrm{O}_{2}^{\overline{2}}$, except for phorbol-myristate- acetate, for which the incubation time was also 30 minutes. The fluorescent product was determined fluorospectrophotometrically $\left(\lambda_{\mathrm{ex}}=315 \mathrm{~nm}\right.$; $\left.\lambda_{\mathrm{em}}=425 \mathrm{~nm}\right)$. Standards of $\mathrm{H}_{2} \mathrm{O}_{2}$ were used to determine the amount of $\mathrm{H}_{2} \mathrm{O}_{2}$ produced by the cells. The intra-assay coefficient of variance was $5 \cdot 8 \%$.

\section{STATISTICAL ANALYSIS}

For statistical comparison, the average values of the Crohn's disease and control groups were evaluated by Student's $t$ test. The results are expressed as the mean \pm SEM. The linear correlation between cellular activity and disease activity was evaluated by the Pearson correlation procedure.

\section{Results}

Under all test conditions except phorbol-myristateacetate stimulation, the mean release of $\mathrm{O}_{2}^{\overline{2}}$ by polymorphonuclear leucocytes from the Crohn's disease groups was the same as for controls (Fig. 1). The maximum stimulation by phorbol-myristateacetate led to decreased production of $\mathrm{O}_{2}^{\overline{1}}$ by the patients' polymorphonuclear leucocytes (mean $430 \pm 91 \mathrm{nmol}$ for untreated and $427 \pm 33 \mathrm{nmol}$ for treated Crohn's disease patients, compared with $607 \pm 67 \mathrm{nmol}$ for the controls). This difference reached significance $(p<0.05)$ for the treated group. Concanavalin $\mathrm{A}$ incubation revealed no difference in $\mathrm{O}_{2}^{\bar{z}}$ production between the control and disease groups. Although cyt $\mathrm{E}$ potentiated the con $\mathrm{A}$ response distinctly (five to six-fold), as has been shown already by several other studies, ${ }^{14}{ }^{15}$ the response in the Crohn's disease groups turned out to be the same as in the control group. Lipopolysaccharide, a potent stimulus for the oxidative metabolism of monocytes (unpublished observations), proved not to be a pre-eminent oxidative stimulus for polymorphonuclear leucocytes as it caused only a moderate (11 to $33 \%$ ) and nonsignificant increase in the $\mathrm{O}_{\dot{2}}^{\overline{2}}$ production in all groups with no differences between the groups.

The production of the other oxygen metabolite that is, $\mathrm{H}_{2} \mathrm{O}_{2}$ - was generally depressed in the untreated Crohn's disease patients, except after stimulation with con A-cyt E (Fig. 2). This impaired $\mathrm{H}_{2} \mathrm{O}_{2}$ production was found relative to both the treated Crohn's disease group and the control group. For instance, after stimulation with phorbolmyristate-acetate the mean $\mathrm{H}_{2} \mathrm{O}_{2}$ production was $52 \pm 6 \mathrm{nmol}$ in the untreated Crohn's disease group, $62 \pm 3 \mathrm{nmol}$ in the treated Crohn's disease group, and $64 \pm 2 \mathrm{nmol}$ in the control group. Lipopolysaccharide incubation resulted in a two-fold increase of the $\mathrm{H}_{2} \mathrm{O}_{2}$ production in the untreated Crohn's 
Fig. 1 Superoxide anion $\left(O_{2}^{-}\right)$ production by polymorphonuclear leucocytes of Crohn's disease patients and controls after incubation with PMA (phorbol-myristate-acetate), LPS (lipopolysaccharide from E coli 0127:B8), and con $A$ (concanavalin A) with or without cyt $E$ (cytochalasin E). $\mathrm{O}_{2}^{-}$production expressed in $\mathrm{nmol} / 30 \mathrm{~min} / 3 \times 10^{6}$

polymorphonuclear leucocytes (mean $\pm S E M)$. CD treated vs controls, $p<0.05$.

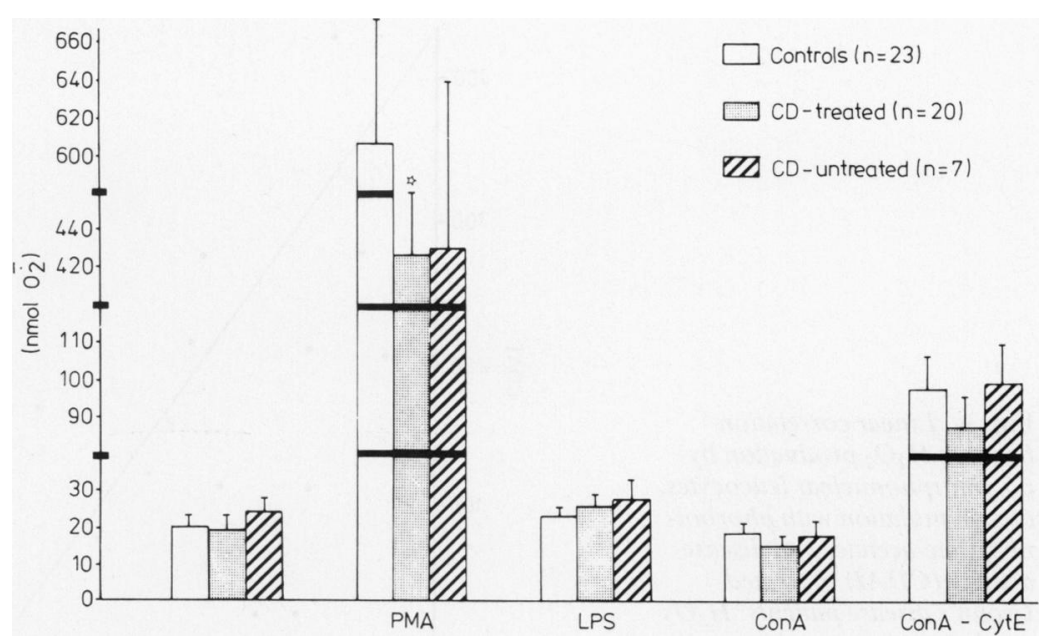

bined $(\mathrm{r}=-0.373 ; \mathrm{p}<0 \cdot 05)$, although production of $\mathrm{H}_{2} \mathrm{O}_{2}$ in the latter group was clearly defective. Under the same conditions we also found a negative correlation between the CDAI and $\mathrm{O}_{\dot{2}}^{\overline{2}}$ production $(r=-0.237$ and $r=-0.149$, respectively) but in neither case was this correlation significant $(p>0 \cdot 1)$.

\section{Discussion}

Several studies on leucocytes in Crohn's disease have shown depressed movement of polymorphonuclear leucocytes into skin windows, and as no other cellular defect was found, some of the authors ascribed this limited motility to an impaired local inflammatory response. ${ }^{45} 18$ Our untreated Crohn's disease patients, however, showed defective production of $\mathrm{H}_{2} \mathrm{O}_{2}$ by polymorphonuclear leucocytes. Although the polymorphonuclear leucocytes of the treated Crohn's disease patients produced normal
Fig. 2 Hydrogen peroxide $\left(\mathrm{H}_{2} \mathrm{O}_{2}\right)$ production by polymorphonuclear leucocytes of Crohn's disease patients and controls after incubation with and without respiratory stimuli. $\mathrm{H}_{2} \mathrm{O}_{2}$ production expressed in $\mathrm{nmol} / 30 \mathrm{~min} / 3 \times 10^{6}$

polymorphonuclear leucocytes (mean $\pm S E M) .{ }^{*} C D$

untreated vs controls, $p<0.05$;

- $C D$ untreated vs $C D$ treated, $p<0.02 ; \star C D$ treated vs controls, $p<0.05$.

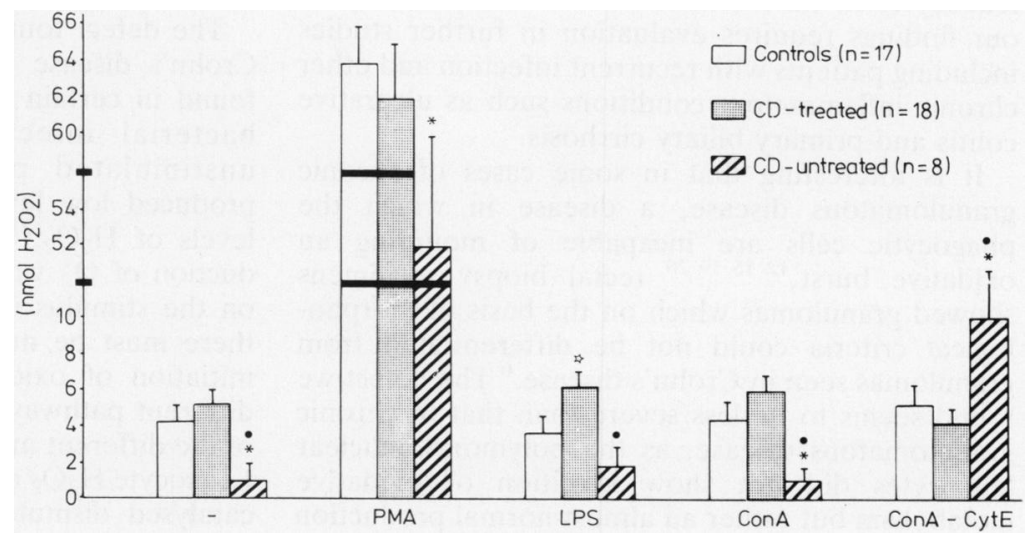


Fig. 3 Linear correlation between $\mathrm{H}_{2} \mathrm{O}_{2}$ production by polymorphonuclear leucocytes, after stimulation with phorbolmyristate-acetate, and disease activity (CDAI) in treated Crohn's disease patients. $\mathrm{H}_{2} \mathrm{O}_{2}$ production expressed in $\mathrm{nmoll}$ $30 \mathrm{~min} / 3 \times 10^{6}$ polymorphonuclear leucocytes.

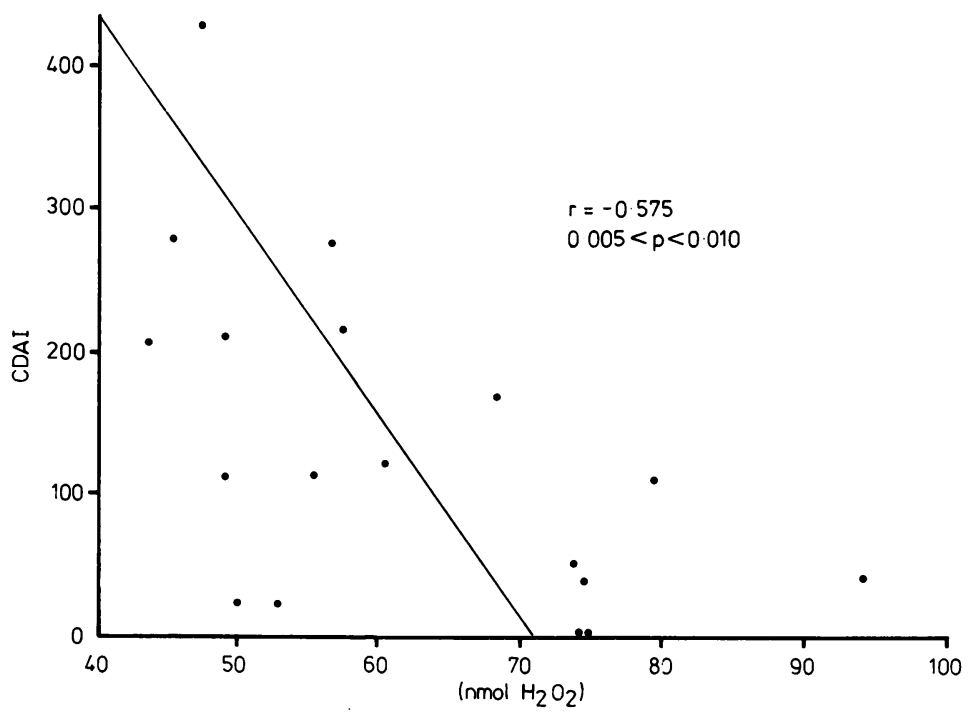

amounts of $\mathrm{H}_{2} \mathrm{O}_{2}$, there was a significant negative correlation between disease activity and $\mathrm{H}_{2} \mathrm{O}_{2}$ production. These findings suggest that in Crohn's disease there is at least a partial intrinsic cellular defect that impairs the production of oxygen metabolites by leucocytes, which might be a primary phenomenon in this disease. As this defect can be corrected by medical treatment, however, it could also be a secondary effect on the primary intestinal process. Follow-up studies on Crohn's disease patients with and without medical treatment will help to elucidate the relationship between this polymorphonuclear leucocyte defect and Crohn's disease. The restoration of oxidative metabolism by medication could be either because of a direct effect on the polymorphonuclear leucocytes or an influence on the production of polymorphonuclear leucocytes in the bone marrow. The specificity of our findings requires evaluation in further studies including patients with recurrent infection and other chronic inflammatory conditions such as ulcerative colitis and primary biliary cirrhosis.

It is interesting that in some cases of chronic granulomatous disease, a disease in which the phagocytic cells are incapable of mounting an oxidative burst, ${ }^{12} 151920$ rectal biopsy specimens showed granulomas which on the basis of morphological criteria could not be differentiated from granulomas seen in Crohn's disease. ${ }^{6}$ The defect we found seems to be less severe than that in chronic granulomatous disease, as the polymorphonuclear leucocytes did not show abolition of oxidative metabolism but rather an almost normal production of the oxygen radical $\mathrm{O}_{\dot{2}}^{\overline{2}}$ and a deficiency in the $\mathrm{H}_{2} \mathrm{O}_{2}$ production.

In some of the studies on leucocytes in Crohn's disease, both nitro blue tetrazolium reduction and luminescence were found to be impaired, ${ }^{489}$ but the techniques used could not discriminate between the different oxygen metabolites produced, and a negative correlation with disease activity was not found. The use of more specific assays to measure the production of both $\mathrm{O}_{2}^{-}$and $\mathrm{H}_{2} \mathrm{O}_{2}$ by leucocytes in Crohn's disease enabled us to detect a partial defect in the oxidative burst. Thus, Crohn's disease resembles chronic granulomatous disease as to the impaired leucocyte function, which together with the locomotor dysfunction of the polymorphonuclear leucocytes might give rise to granuloma formation in the intestine as a compensatory mechanism for the clearance of foreign material.

The defect found in the oxidative metabolism in Crohn's disease also appears to differ from that found in certain patients suffering from recurrent bacterial infections. ${ }^{21} 22$ In these patients, unstimulated polymorphonuclear leucocytes produced low levels of $\mathrm{O}_{\dot{2}}^{\bar{j}}$ but normal or raised levels of $\mathrm{H}_{2} \mathrm{O}_{2},{ }^{21}$ and under stimulation the production of $\mathrm{O}_{2}^{-}$was normal or impaired, depending on the stimulus used. These findings indicate that there must be more than one mechanism for the initiation of oxidative metabolism, and also that different pathways are followed for the production of the different metabolites of the respiratory burst. Leucocyte $\mathrm{H}_{2} \mathrm{O}_{2}$ might be formed by spontaneous or catalysed dismutation of superoxide anion or by 
direct divalent reduction of oxygen. ${ }^{23}{ }^{24}$ The present study has provided further evidence that polymorphonuclear leucocytes have another pathway for the production of $\mathrm{H}_{2} \mathrm{O}_{2}$ besides the dismutation of $\mathrm{O}_{2}^{\bar{z}}$.

These findings indicate the interesting occurrence of depressed $\mathrm{H}_{2} \mathrm{O}_{2}$ production in the presence of normal $\mathrm{O}_{2}^{\bar{z}}$ production in Crohn's disease. Further studies on the oxidative metabolism of polymorphonuclear leucocytes in Crohn's disease may help to elucidate the basic defect and yield new insights into the pathogenesis of Crohn's disease.

This study was presented in part at the World Congress of Gastroenterology, Stockholm, Sweden, in June 1982. The authors wish to thank Dr W Beeken for a critical reading of the manuscript and Gabrielle W M Verhoef for typing and Mrs I Seeger for reading the English text.

\section{References}

1 Ward M. The pathogenesis of Crohn's disease. Lancet 1977; 2: 903-6.

2 Ward M. Pathocytic function in Crohn's disease. $Z$ Gastroenterol 1979; 17 suppl: 116-24.

3 Segal AW, Loewi G. Neutrophil dysfunction in Crohn's disease. Lancet 1976; 2: 219-21.

4 Wandall JH, Binder V. Leucocyte function in Crohn's disease. Gut 1982; 23: 173-80.

5 O'Morain C, Segal AA, Walker D, Levi AJ. Abnormalities of neutrophil function do not cause the migration defect in Crohn's disease. Gut 1981; 22: 817-22.

6 Ament ME, Ochs HD. Gastrointestinal manifestations of chronic granulomatous disease. N Engl J Med 1973; 288: 382-7.

7 Ward M, Eastwood MA. The nitro blue tetrazolium test in Crohn's disease and ulcerative colitis. Digestion 1976; 14: 179-83.

8 Worsaae N, Staehr Johansen K, Christensen KC. Impaired in vitro function of neutrophils in Crohn's disease. Scand J Gastroenterol 1982; 17: 91-7.

9 Kelleher D, Feighery C, Weir DG. Neutrophil luminescence in chronic inflammatory bowel disease (CIBD). [Abstract] Gut 1982; 23: A895-T22.

10 Best WR, Becktel JM, Singleton JW, Kern F. Development of a Crohn's disease activity index (National cooperative Crohn's disease study). Gastroenterology 1976; 70: 439-44.

11 Roos D, Loos JA. Changes in the carbohydrate metabolism of mitogenetically stimulated human peripheral lymphocytes. Biochem Biophys Acta 1970; 222: $565-82$.

12 Johnston RB, Keele BB, Misra HP et al. The role of superoxide anion generation in phagocytic bacterial activity. Studies with normal and chronic granulomatous disease leucocytes. J Clin Invest 1975; 55: 1357-72.

13 DeChatelet LR, Shirley PS, Johnston RB. Effect of Phorbol myristate acetate on the oxidative metabolism of human polymorphonuclear leucocytes. Blood 1976; 47: 545-55.

14 Zabucchi G, Berton G, Soranzo MR. Mechanism of the potentiating effect of cytochalasin $B$ on the respiratory burst induced by Concanavalin $A$ in leucocytes. FEBS Lett 1982; 125: 165-70.

15 Nakagawara A, Nabi FBZ, Minakani S. An improved procedure for the diagnosis of chronic granulomatous disease, using concanavalin A and cytochalasin E. Clin Chim Acta 1977; 74: 173-6.

16 Rossi F, Bellavite P, Dobrina A, Dri P, Zabucchi G. Oxidative metabolism of mononuclear phagocytes. In: van Furth R, ed. Mononuclear phagocytes: functional aspects. The Hague: Martinus Nijhoff, 1980: 1187-214.

17 Guilbault CG, Brignac P, Zimmer M. Homovanillic acid as a fluorometric substate for oxidative enzymes. Anal Chem 1968; 40: 190-7.

18 D’Amalio R, Rossi P, LeMoli S, Ricci R, Montano S, Pallone $P$. In vitro studies on cellular and humoral chemotaxis in Crohn's disease using the under agarose gel technique. Gut 1980; 22: 566-70.

19 Nathan DG, Baehner RL, Weaver DK. Failure of nitro blue tetrazolium reduction in the phagocytic vacuoles of leucocytes in chronic granulomatous disease. J Clin Invest 1969; 48: 1895-904.

20 Takeshige K, Matsumoto T, Shibata R, Minakani S. Simple and rapid method for the diagnosis of chronic granulomatous disease, measuring hydrogen peroxide and superoxide anions released from leukocytes in whole blood. Clin Chim Acta 1979; 92: 329-35.

21 Weening RS, Roos D, Weemaes CMR, Homan-Müller JWT, van Schaik MLJ. Defective initiation of the metabolic stimulation in phagocytizing granulocytes: a new congenital defect. J Lab Clin Med 1976; 88: 757-68.

22 Harvath L, Andersen BR. Defective initiation of oxidative metabolism in polymorphonuclear leucocytes. N Engl J Med 1979; 300: 1130-5.

23 Nathan $C F$. The release of hydrogen peroxide from mononuclear phagocytes and its role in extracellular cytolosis. In: van Fruth R, ed. Mononuclear phagocytes: functional aspects. The Hague: Martinus Nijhoff, 1980: 1166-83.

24 Rosen H, Klebanoff SJ. Bactericidal activity of a superoxide anion generating system. A model for the polymorphonuclear leukocyte. J Exp Med 1979; 149: 27-39. 